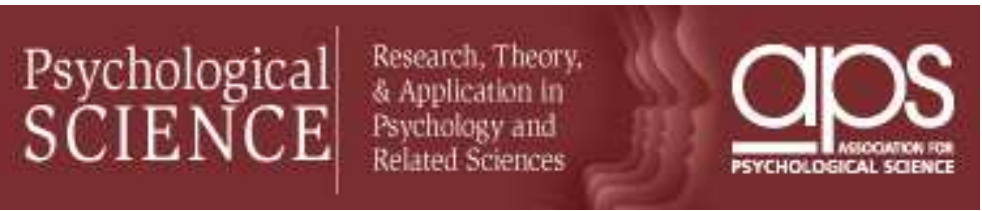

Global Social Identity and Global Cooperation

\begin{tabular}{|c|c|}
\hline Journal: & Psychological Science \\
\hline Manuscript ID: & PSCI-10-1341.R2 \\
\hline Manuscript Type: & Research article \\
\hline $\begin{array}{r}\text { Date Submitted by the } \\
\text { Author: }\end{array}$ & $\mathrm{n} / \mathrm{a}$ \\
\hline Complete List of Authors: & $\begin{array}{l}\text { Buchan, Nancy; University of South Carolina, Sonoco International } \\
\text { Business Department } \\
\text { Brewer, Marilynn; University of New South Wales, School of } \\
\text { Psychology } \\
\text { Grimalda, Gianluca; Jaume I University, Economics Department } \\
\text { Wison, Rick; Rice University, Department of Political Science } \\
\text { Fatas, Enrique; University of Valencia, Laboratory for Research in } \\
\text { Experimental Economics } \\
\text { Foddy, Margaret; University of Sydney, Department of Psychology }\end{array}$ \\
\hline Keywords: & Cooperation, Decision Making \\
\hline
\end{tabular}


Global Social Identity and Global Cooperation

\author{
Nancy R. Buchan \\ University of South Carolina \\ Marilynn B. Brewer \\ University of New South Wales \\ Gianluca Grimalda \\ IST Lisbon \\ Rick K. Wilson \\ Rice University \\ Enrique Fatas \\ University of Valencia \\ Margaret Foddy \\ University of Sydney
}




\begin{abstract}
This research examines the question of whether the psychology of social identity can be extended to enhance cooperative motives in the context of very large, global collectives. Our data come from a multi-national study of choice behavior in a multi-level public goods dilemma conducted among samples drawn from the general populations of the United States, Italy, Russia, Argentina, South Africa and Iran. Results demonstrate that an inclusive social identification with the world community is a meaningful psychological construct that plays a role in motivating cooperation that transcends parochial interests. Self-reported identification with the world as a whole predicts behavioral contributions to a global public good above and beyond expectations about what other participants are likely to contribute. Furthermore, global social identification is conceptually distinct from general attitudes about global issues, with unique effects on cooperative behavior.

Keywords: Social identity, cooperation, social dilemma, goal transformation, globalization
\end{abstract}


Global Social Identity and Global Cooperation

More than ever before in human history, many of our most pressing problems involve global interdependence. Because of phenomena associated with global warming, destruction of rainforests, and instability in international markets, decisions made by actors in one locality have consequences for the physical environment and economic opportunities of people at remote distances. Addressing such problems requires cooperation that transcends national boundaries.

Many global problems are social dilemmas - situations in which individuals must choose between behaviors serving self-interest and behaviors benefitting the collective welfare. At each dilemma decision point, it is in the individual's interest to act selfishly, but if everyone acts selfinterestedly, ultimately everyone in the collective is worse off (Dawes, 1980; Messick \& Brewer, 1983). The public goods dilemma exemplifies this situation. Public goods depend on individual contributions to be created, but once created, the public good is available to all members of a collective regardless of their level of contribution. Thus, each individual maximizes self interest by benefitting from the resource without contributing anything. But if everyone in the collective fails to contribute, the public good is lost, benefitting no one. Collectively, everyone is better off if all contribute, even though cooperation involves self-sacrifice at the individual level.

Public goods dilemmas have been studied extensively by behavioral economists, political scientists, and social psychologists, and laboratory and field research is instructive about the conditions under which individuals will behave cooperatively even when contributing resources to a group of anonymous strangers. In general, when shared group identity is made salient, or when group members are strongly identified with the collective, levels of cooperation are significantly higher than when no shared identity is available or group identification is weak (e.g,. DeCremer \& van Vugt, 1999; Wit \& Kerr, 2002). 
Although a number of mechanisms have been proposed to explain why social identification with the relevant collective enhances self-sacrificial cooperation on behalf of that group (Brewer, 2008); we focus on two that have received the most attention-expectancies and values.

Expectations about Others

One theory is based upon the general expectancy that others will be cooperative within the ingroup (Brewer, 1986; Yamagishi \& Kiyonari, 2000), that others cooperate with me because we are members of the same group (Foddy, Platow \& Yamagishi, 2009). Such norms of "generalized reciprocity" are strong in intra-group interactions and weaker or absent across group boundaries (Tanis and Postmes, 2005; Yamagishi, Jin, \& Kiyonari, 1999). Expecting that others will behave cooperatively reduces the fear that one's own cooperation will be taken advantage of, making cooperation compatible with individual incentives. Thus, it is tempting to believe that if ingroup membership increases trust (i.e., expectations that other ingroup members will cooperate), this is sufficient to account for the effect of ingroup identity on all intragroup cooperative behavior.

However, expectations of others' intentions to cooperate are not of themselves sufficient to generate cooperative behavior, especially in large, dispersed groups (e.g., De Cremer, Dewitte, $\&$ Snyder, 2001). Although trust reduces fear, it does not eliminate the self-interested benefit of noncooperation (greed). If everyone else is expected to cooperate, noncooperation takes advantage of others' contributions to group welfare and maximizes personal outcomes. In very large collectives, where monitoring and sanctioning of nonreciprocity are minimal, this temptation to take advantage of others' cooperation is great. 


\section{Goal Transformation}

A second explanation is that strengthening group identity increases the value people attach to the group's welfare as opposed to their personal welfare. When individuals attach their sense of self to their group membership, they see themselves as interchangeable components of a larger social unit (Turner, Hogg, Oakes, Reicher, \& Wetherell, 1987). As a result of this redefinition of the self, pursuing the group's interest and concern with the group's welfare becomes a direct expression of self-interest, that is, collective and personal interest are interchangeable (Brewer, 1991; De Cremer and Van Vugt, 1999; Kramer \& Brewer, 1986).

De Cremer and van Dijk (2002) tested this idea in the context of a multiple round public goods dilemma. Notification that their group had failed to provide the public good in the earlier round motivated strong social identity participants to contribute significantly more in the session following feedback, consistent with the goal-transformation hypothesis. In contrast, weak group identifiers reduced their contributions in the second round, as would be predicted based on expectations about other group members' behavior.

Prior research on social identity and collective cooperation has involved relatively small laboratory groups or local communities. Extant theories of the origins of altruistic cooperation in humans suggest that large-scale cooperation is parochial in nature (e.g., Bernhard, Fischbacher, \& Fehr, 2006; Choi \& Bowles, 2007), and biased in favor of ingroups such as ethnic groups, nations, or religious communities. This leaves open the question of whether social identity can enhance cooperation in the context of very large, global collectives. The current study examines the influence of social identity on behavior in a multi-level public goods dilemma where participants choose whether to make contributions that benefit the self, a local group, or a worldwide group. 
The study was conducted in six countries representing high variability in environmental factors. The US, Italy, Argentina, South Africa, Russia and Iran differ greatly in levels of social, economic and political globalization, as measured by the aggregated country-level globalization index (CGI) ${ }^{1}$ produced by the Centre for the Study of Globalization and Regionalisation at the University of Warwick, $\mathrm{UK}^{2}$. Furthermore, our sample was drawn from the general population of each country - men and women, aged 18-75 representing all levels of social economic status providing high variability in demographic factors.

The first study from this research (Buchan et al. 2009) demonstrated that contributions to the worldwide group varied across countries as a function of the level of country-wide or individual-level globalization in each nation, such as the level of social connectivity via internet connections, or economic connectivity via trade or purchase of foreign products. At both the country and individual level, higher globalization was associated with greater contribution to a world collective. In the present study we examine whether there are psychological variables that are robust in predicting individual cooperative behaviors across this variation in social and economic conditions in our research population.

More specifically, the goals of the present research are, first, to demonstrate empirically the existence of an identification with the world at large that transcends parochial interests in motivating cooperation in a global public goods dilemma, and second, to test whether the influence of global social identity on cooperation exists independently of the effect of expectations concerning how others in the world collective will behave. 


\section{Method}

\section{The Sample}

Within each country the research was conducted in a large metropolitan area and in surrounding areas that were less globalized in nature. For example, in Russia the research occurred in Kazan, a globalized city in Tatarstan, and in more rural outposts. The metropolitan area in the United States was Columbus, Ohio; in South Africa, Johannesburg; in Italy, Milan; in Argentina, Buenos Aires, and in Iran, Tehran.

A quota sampling recruitment method was used based on three characteristics: gender; age (18- 30, 31-50, 51-75); socioeconomic status (low, medium, high). These characteristics produced an 18 cell matrix, yielding approximately 190 participants per country for a total of 1195 participants. The implementation of standardized experimental instructions and procedures in each country ensured the cross-country comparability of the datasets. All participants possessed at least a $4^{\text {th }}$ grade reading level, had lived in the locality for at least one year, and were citizens of the country studied. ${ }^{3}$

Experimental Paradigm

Individual propensities to cooperate with local and global others were assessed in a Multi-level Sequential Contribution (MSC) experiment. The MSC protocol resembles that of a standard multi-level public goods experiment (Blackwell \& McKee, 2003; Wit \& Kerr, 2002). The full experiment consisted of three contribution decisions-- the local, national, and global public goods. In the current research we focused only on the local and global (world) decision data $^{4}$. For each decision participants were given 10 tokens. One token was worth the purchasing power equivalent of US $\$ 0.50$. 
The experiment was conducted with a maximum of 24 and a minimum of four participants per session. Privacy barriers were constructed between participants so that their choices would not be influenced by observing what others were doing. At each session's start, participants were told that they would be making decisions with other people, some of whom were from their local community (but perhaps not currently in the room), some from elsewhere in the same country, and some from other countries. Furthermore, some participants may have already made their decisions; the participant's choices and the choices of others would be matched by computer at the end of the session and payoffs would be determined.

Because of the logistical impossibility of conducting the experiment simultaneously in six countries, we relied on a dynamic matching algortithm where past participants' decisions were used to determine the payoffs of current participants whose own decisions entered the dataset as the experiment ensued. By this method, participants' outcomes were determined by their decision and those made by arbitrarily selected groups of participants from the participant's locality, country, or other countries around the world. Participants received payoffs at the end of the experiment, thus no feedback was provided regarding decisions during the session.

In the Local Decision, participants faced the same incentives as in a standard public goods game. This two-choice decision familiarized participants with the experimental task and established baseline levels of cooperation. In the Local Decision, participants decided how to allocate tokens between their "personal" and "local" accounts. Each token put into the personal account was saved and worth a single token. Each token put into the local account was doubled by the experimenter and shared equally between the participant and three other (anonymous) participants from the same local area. Likewise, the participant received an equal share from the tokens that the other three local participants put into their local accounts. Therefore, the return to 
each individual for each token allocated to the local account - the Marginal Per Capita Return (MPCR) - was 0.5. In contrast, the return to the group - the marginal social return (MSR) equaled 2. A selfish individual would allocate all their tokens to their personal account because of its larger return relative to the collective account. Were all individuals selfish, each participant would keep their initial 10 tokens. In contrast, were all individuals of a group to allocate their endowment to their local accounts, this would result in a 20 token payoff tokens to each group member.

After the instructions were read, participants worked several example decisions to make sure they understood the nature of the task and the effects of their own and others' choices on their outcomes. Finally, participants made their actual allocations by putting red tokens into envelopes labeled PERSONAL and LOCAL. An experiment assistant collected the envelopes took them into the control room where the tokens were recorded in the algorithm and payoffs calculated.

In the World Decision participants chose how much to allocate among their personal account, their local account and their "world" account. The structure of incentives of the personal and local accounts was identical to that of the Local Decision. Tokens placed in the World account were instead tripled by the experimenter and split equally among a "world" group of 12 people. The world group was made up of the participant, a new group of three (anonymous) local people benefiting from the local account - plus two groups of four people from different countries. Participants were not told which specific countries these other participants were from, but were informed that these countries were from any of the four continents where the research was being conducted. Each participant received a one-twelfth share of the allocations that all twelve people made to their world accounts. 
The MPCR from allocations to the world account equals .25; less than the MPCR from the Local account, .50. In contrast, the MSR of contributions to the World account equals 3.0; larger than the MSR of the Local account, 2.0. Consequently, if all individuals allocated their endowment to their World account in the World Decision, this would result in a larger payoff (30 tokens) to each participant than if all allocated their endowment to their local accounts (20 tokens). This structure of incentives characterizes a multi-level public goods dilemma. A contribution to a higher-order public good typically benefits a larger number of people but at a smaller rate of return than a contribution to a lower-order public good.

Again participants completed several example decisions to be certain they understood the nature of the nested global public good. Participants then made their allocations by putting yellow tokens into envelopes labeled PERSONAL, LOCAL and WORLD and the envelopes were collected.

Expectancy Measure

After completing all allocation decisions, participants answered questions regarding their expectations of group members' cooperative behavior. Each participant was asked how many tokens they believed their fellow members in the Local group allocated to the Local account in the Local Decision. For example:

In Decision 1 you had 10 red tokens. So did everyone else. You could put your tokens into your "Personal" envelope or into your Kazan envelope. The other three people in your local group could also choose to put tokens into their own personal envelope or into the Kazan envelope. Please answer the following question.

How much do you think the other three people put into the Kazan envelopes in total (there is a maximum of 30 red tokens that they could put into them):

Then on a separate form they were asked how many tokens they believed their fellow members in the Local group allocated to the Local account in the World Decision and how many 
tokens their fellow members in the World group allocated to the World account in the World Decision.

This type of expectancy measure is a common operationalization of trust with the expectancy assessment coming after the contribution decision has been made. Because of this, any relationship between trust and cooperation is causally ambiguous; it is possible that individuals are projecting their own choices onto fellow group members or using expectations to justify previous actions (Dawes, McTavish, \& Shaklee, 1977). For this reason, we assessed expectancies about earlier decisions after some delay. Despite this, we assume that the relationship between an individual's own contribution decision and their reported expectancies about others' contributions is a mutually reciprocal one.

\section{Questionnaire Measures}

Participants next completed a questionnaire prior to receiving their payoffs. Responses to this questionnaire provided data for our measures of social identity, concern for global issues, a globalization index used in other phases of this research, as well as basic demographic information on participant sex, age, education, and income level ${ }^{5}$.

Social Identity. A three-item measure assessed social identification at the levels of the local community, the nation, and the world. For example, in Kazan, Russia these items read: "How strongly do you feel attachment to your community in Kazan?" "How strongly do you feel attachment to your community in Russia?" How strongly do you feel attachment to the world as a whole?" "How strongly do you define yourself as a member of your community in Kazan?" "in Russia," “... of the world as a whole?" "How close do you feel to other members of your community in Kazan?" “... in Russia,"”... to the world as a whole?" Each item was Likertscaled from 1 to 4 where $4=$ very much and $1=$ not at all. 
The Cronbach alpha of the three social identity items was .78 at the local level, .72 at the national level, and .75 at the world level. The social identification scale at each level (Local Social Identity, (LSI), National Social Identity, (NSI), and Global Social Identity, (GSI)) was summated with all three items equally weighted, resulting in possible scores ranging from 3 to 12.

Concern for Global Issues. Since identification is expected to be associated with values that include concern for global welfare, a measure of concern was included in the questionnaire, composed of four items. Participants were asked, "How concerned are you with the following issues: "Global warming," "The spread across the planet of potentially dangerous diseases (e.g. HIV, SARS, Bird flu)," "Making the action of International Criminal Courts of Justice more effective," "The persistent gap between rich and poor people around the world". Each item was scaled from 1 to 4 where $4=$ Very concerned and $1=$ Not at all concerned. Again the items were summed and equally weighted to form the Concern variable (Cronbach's $\alpha=.64$ ).

\section{Results}

Of the 1145 participants in the study, there were complete dependent variables (that is, contribution data for both the Local and World accounts) for 1122. Among these 1122 individuals, missing questionnaire data occurred randomly across people and countries. To address this we used PROC MI, a multiple imputation procedure in SAS, to represent a random sample of the missing values (Rubin 1996).

\section{Cross-national comparisons}

Table 1 provides basic descriptive statistics from our sample across countries on the key measures of interest; contributions to the world account, expectations about others' contributions to the world account, global social identity (GSI), and concern for global issues. The countries 
are listed on the table in ascending order of their country level globalization (CGI). Given the differences among countries in globalization and also in mean levels of predictor variables, country was always included as a control variable in analyses of individual level effects. ${ }^{6}$ Insert Table 1 about here

\section{Intercorrelations}

The individual level intercorrelations between world contributions, expectations, concern, and all levels of social identity are shown in Table 2. As expected, there is a high and significant correlation between world contributions and expectations, consistent with the hypothesized reciprocal relationship between the two measures. ${ }^{7}$ We also see the predicted significant relationship between concern for global issues and global social identity (GSI), both of which are correlated with world contributions. Despite the significant intercorrelations among the social identity measures, only the measure of global social identity has a significant bivariate correlation with world contributions.

Insert Table 2 about here

\section{Regression Analysis}

At the heart of our analysis is the prediction of world contributions from GSI, concern, and expectations, controlling for country (dummy coded), demographic variables, baseline cooperation (local contributions) and local and national identity. The results of this regression are shown in Table 3. As anticipated, expectation is the most important variable in the model, affirming the reciprocal relationship between expectation of cooperative behavior and contributions. Importantly however, GSI does have a significant independent effect on global cooperation, above and beyond the effect of expectation, even after the influences of income, 
education, baseline cooperation, local and national identity and country have been accounted for. $^{8}$

Insert Table 3 about here

Furthermore, although concern is correlated with world contributions, it is not a significant predictor of contributions when GSI and expectations are included in the model, supporting the contention that social identification has unique effects on cooperative behavior, distinct from general attitudes about global issues.

\section{Discussion}

The results from this multi-nation study suggest that an inclusive social identification with the world community is a meaningful psychological construct and that it plays a role in motivating cooperation that transcends parochial interests. Importantly, self-reported identification with the world as a whole predicts behavioral contributions to a global public good independent of expectations about what other participants in the group are likely to contribute. Although individuals high in global identification did generally have positive expectations about others' contributions, the size of their own contributions was systematically higher than what would be predicted from expectations alone. This is in line with the hypothesized mechanism of goal transformation; global social identity is associated with a desire to maximize collective outcomes and motivates individuals to contribute to collective goods regardless of whether they expect a return on their investment or not.

Although our empirical evidence for the role of global social identity in motivating global cooperation is purely correlational, the present study has the strength of a behavioral outcome measure. Participants in this study who described themselves as identified with the world community literally "put their money where their mouth is" in making decisions to contribute 
significant resources at potential cost to personal wealth. The monetary outcomes in the experiment were not trivial; across the three decision tasks participants had the potential to acquire the purchasing power equivalent of $\$ 40$ U.S. or more, depending on what they and others contributed to the collective accounts. Yet for each token that an individual contributed to the world account, he/she could only count on receiving .25 as their share of the collective good; choosing to contribute was a risky choice that sacrificed self-interest while increasing the collective wealth. Further, the nature of our sample - taken from the general population of six countries from around the world - is unique and adds to the external validity of our findings. Our participants - men and women ranging in age from 18 to 75 - represented a broad spectrum of levels of socio and economic status in countries that themselves ranged widely in aggregate levels of economic, social, and political globalization.

Across this range of countries and participant characteristics, self-reported identification with the world as a whole emerged as a unique predictor of size of contributions to a global collective. Such social identity-based cooperation is particularly important for large groups facing public goods dilemmas. In the absence of close monitoring and sanctioning of noncooperation, some basis for intrinsic motivation to cooperate and contribute to the group welfare is essential. Cooperation that does not depend exclusively on reciprocal trust may be required to solve global social dilemmas under conditions where well-developed group norms, mutual recognition of shared group identity, and group sanctions for noncooperation are absent. Symbolic identification with "the world as a whole" may serve to generalize the psychology of ingroup behavior to a more inclusive collective that transcends the requirement of defined group boundaries. 


\section{Acknowledgments}

We gratefully acknowledge the support of the NSF (Grants \#0652277 and \#0652310).

We thank Donna Bahry, Patricio Dalton, Iain Edwards, and Saul Keifman, among many others, for their valuable contribution to the fieldwork, and, in particular, Warren Thorngate at Carlton University for making data collection in Iran possible. Organizational support from CIDED in Argentina and Econometica in Italy is also acknowledged. 


\section{References}

Bernhard, H., Fischbacher, U., \& Fehr, E. (2006). Parochial altruism in humans. Nature, 442, 912-915.

Blackwell, C., \& McKee, M. (2003). Only for my own neighborhood? Preferences and voluntary provision of local and global public goods. Journal of Economic Behavior and Organization 52, 115-131.

Brewer, M. B. (1986). Ethnocentrism and its role in interpersonal trust. In M. Brewer \& B. Collins (Eds.), Scientifiic inquiry and the social sciences: A volume in honor of Donald T. Campbell (pp. 345-360). San Francisco: Jossey-Bass.

Brewer, M.B. (1991). The social self: On being the same and different at the same time. Personality and Social Psychology Bulletin, 17, 475-482.

Brewer, M. B. (2008). Depersonalized trust and ingroup cooperation. In J. Krueger (Ed.), Rationality and social responsibility (pp. 215-232). New York: Psychology Press.

Brewer, M. B., \& Kramer, R. M. (1986). Choice behavior in social dilemmas: Effects of social identity, group size, and decision framing. Journal of Personality and Social Psychology, $50,543-549$.

Buchan, N., Grimalda, G., Wilson, R., Brewer, M., Fatas, E., \& Foddy, M. (2009). Globalization and human cooperation. Proceedings of the National Academy of Sciences, 106, 41384142.

Choi, J, \& Bowles, S. (2007). The coevolution of parochial altruism and war. Science, 318, 636640.

Dawes, R.M. (1980). Social dilemmas. Annual Review of Psychology, 31, 169-193. 
Dawes, R. M., McTavish, J., \& Shaklee, H. (1977). Behavior, communication, and assumptions about other people's behavior in a commons dilemma situation. Journal of Personality and Social Psychology, 35, 1-11.

De Cremer, D., Dewitte, S., \& Snyder, M. (2001). The less I trust, the less I contribute (or not)? The effects of trust, accountability and self-monitoring in social dilemmas. European Journal of Social Psychology, 31, 93-107.

De Cremer, D., \& van Dijk, E. (2002). Reactions to group success and failure as a function of identification level: A test of the goal-transformation hypothesis in social dilemmas. Journal of Experimental Social Psychology, 38, 435-442.

De Cremer, D., \& Van Vugt, M. (1999). Social identification effects in social dilemmas: A transformation of motives. European Journal of Social Psychology, 29, 871-893.

Foddy, M., Platow, M., \& Yamagishi, T. (2009). Group-based trust in strangers: The role of stereotypes and expectations. Psychological Science, 20, 419-422.

Kramer, R. M., \& Brewer, M. B. (1986). Social group identity and the emergence of cooperation in resource conservation dilemmas. In H. Wilke, D. Messick, \& C. Rutte (Eds.), Experimental social dilemmas (pp. 129-137). Frankfurt, Germany: Verlag Peter Lang.

Messick, D.M., \& Brewer, M.B. (1983). Solving social dilemmas: A review. In L. Wheeler \& P. Shaver (Eds.). Review of Personality and Social Psychology (Vol. 4, pp. 11-44). Beverly Hills CA: Sage.

Rubin, D. (1996). Multiple imputation after 18+ years. Journal of the American Statistical Association, 91, 473-489. 
Tanis, M., \& Postmes, T. (2005). A social identity approach to trust: Interpersonal perception, group membership and trusting behaviour. European Journal of Social Psychology, 35, 413-424.

Turner, J. C., Hogg, M., Oakes, P., Reicher, S., \& Wetherell, M. (1987). Rediscovering the social group: A self-categorization theory. Oxford: Basil Blackwell.

Wit, A. P., \& Wilke, H. (1999). The effect of social categorization on cooperation in three types of social dilemmas. Journal of Economic Psychology, 13, 135-151.

Wit, P, \& Kerr, N. L. (2002). Me versus just Us versus All: Categorization and cooperation in nested social dilemmas. Journal of Personality and Social Psychology, 83, 616-637.

Yamagishi, T., \& Kiyonari, T. (2000). The group as the container of generalized reciprocity. Social Psychology Quarterly, 63, 116-132.

Yamagishi, T., Jin, N., \& Kiyonari, T. (1999). Bounded generalized reciprocity: Ingroup boasting and ingroup favoritism. Advances in Group Processes, 16, 161-197. 


\section{Footnotes}

\footnotetext{
${ }^{1}$ The countries have the following CGI scores (on a 0-1 scale): Iran .1996, South Africa .3398. Argentina .3839, Russia .6020. Italy .6722, USA .8700.

${ }^{2}$ See Lockwood B, Redoano M (2005) http://www2.warwick.ac.uk/fac/soc/csgr/index/

3 Further detailed description of the sampling, procedures, experimental materials, and all instruments used in this research is available at http://www.pnas.org/content/suppl/2009/03/01/0809522106.DCSupplemental/Appendix PDF.pdf 4 Contributions to the nation collective in Decision 2 were highly correlated with size of contributions to the global collective in Decision $3(\mathrm{r}=.68, \mathrm{p}<.01)$. In general, individuals who made sizeable contributions at the global level also did so at the national level, but not necessarily vice versa. Accounting for differences between national and global collective contributions was beyond the scope of the present study.

5 Income denotes the income decile to which a participant responded s/he belongs within his/her country's income distribution; it is a country-specific measure.

6 Country was entered as five dummy coded variables (with the U.S. as the baseline case), so analyzing interaction terms would have added five more variables to the model. Exploring the regression results within each country, the effect of global identity was positive in every case. The size of the effect did vary from country to country, but in no systematic manner (specifically, did not vary systematically with country level globalization).

7 However in at least three countries, the average expectation of others' contributions was substantially higher than the mean of own contributions, suggesting that, for some participants at least, trust in others' generosity provided an opportunity for exploitation rather than reciprocation.
} 
Table 1

Means and Standard Deviations for Primary Measures: Cross-National Comparisons

\begin{tabular}{|c|c|c|c|}
\hline Country & Primary Measure & Mean & SD \\
\hline IRAN & World Contributions & 3.42 & 2.81 \\
\hline \multirow[t]{3}{*}{$(N=179)$} & Expectation & 3.06 & 3.23 \\
\hline & GSI & 6.63 & 2.12 \\
\hline & Concern & 2.57 & 0.88 \\
\hline \multicolumn{4}{|l|}{ SOUTH } \\
\hline AFRICA & World Contributions & 3.81 & 1.98 \\
\hline \multirow[t]{3}{*}{$(N=159)$} & Expectation & 3.73 & 2.77 \\
\hline & GSI & 7.88 & 2.76 \\
\hline & Concern & 2.81 & 0.84 \\
\hline ARGENTINA & World Contributions & 3.81 & 2.84 \\
\hline \multirow[t]{3}{*}{$(N=201)$} & Expectation & 5.19 & 2.80 \\
\hline & GSI & 7.24 & 2.57 \\
\hline & Concern & 2.84 & 0.75 \\
\hline RUSSIA & World Contributions & 4.70 & 2.66 \\
\hline \multirow[t]{3}{*}{$(N=207)$} & Expectation & 5.89 & 2.79 \\
\hline & GSI & 7.85 & 2.47 \\
\hline & Concern & 2.52 & 0.79 \\
\hline ITALY & World Contributions & 4.49 & 2.87 \\
\hline \multirow[t]{3}{*}{$(N=205)$} & Expectation & 5.15 & 2.71 \\
\hline & GSI & 8.89 & 2.01 \\
\hline & Concern & 2.76 & 0.74 \\
\hline USA & World Contributions & 5.79 & 3.16 \\
\hline \multirow[t]{3}{*}{$(N=171)$} & Expectation & 5.78 & 2.75 \\
\hline & GSI & 8.29 & 2.35 \\
\hline & Concern & 2.97 & 0.85 \\
\hline
\end{tabular}


Page 23 of 24

Manuscript under review for Psychological Science

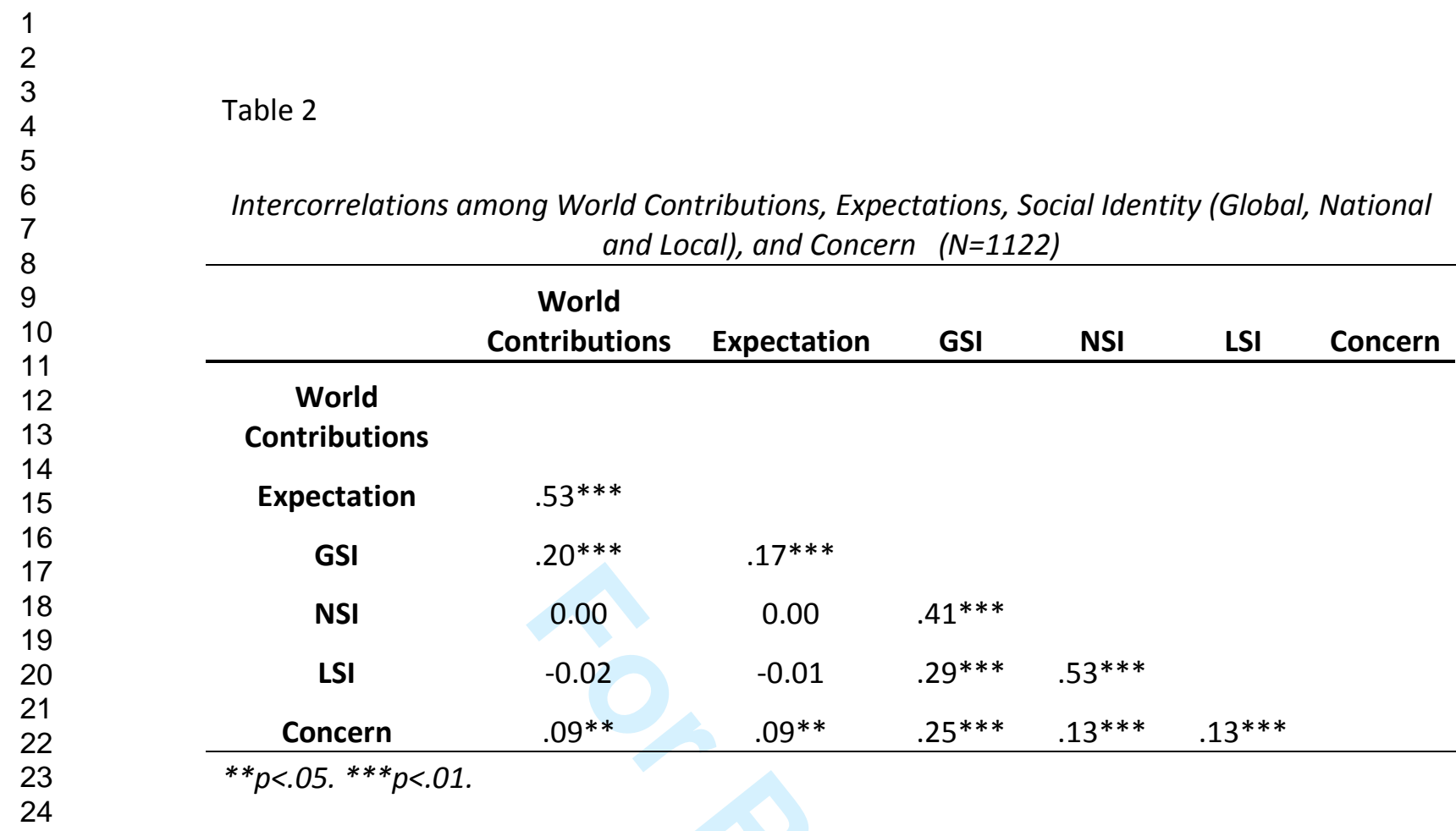$$
8
$$$$
9
$$$$
10
$$$$
11
$$$$
12
$$$$
13
$$$$
14
$$$$
15
$$$$
16
$$$$
17
$$$$
18
$$$$
19
$$$$
20
$$$$
21
$$$$
22
$$$$
23
$$$$
24
$$$$
\text { Intercorrelations among World Contributions, Expectations, Social Identity (Global, National }
$$$$
\text { and Local), and Concern ( } N=1122)
$$$$
\text { World }
$$$$
\text { Contributions Expectation GSI NSI } \quad \text { LSI Concern }
$$$$
\text { World }
$$$$
\text { Contributions }
$$$$
\text { Expectation } \quad .53^{* * *}
$$$$
\text { GS }
$$$$
\text { RSI }
$$$$
\text { LI }
$$$$
.20 * * *
$$$$
0.00
$$$$
\text { Concern }
$$$$
-0.02
$$$$
{ }^{* *} p<.05 .{ }^{* * *} p<.01 \text {. }
$$$$
.09 * *
$$$$
.17^{* * *}
$$$$
0.00
$$$$
.41 * * *
$$$$
-0.01
$$$$
.29 * * *
$$$$
.53^{* * *}
$$$$
.09 * *
$$$$
.25^{* * *}
$$$$
.13^{* * *} \quad .13^{* * *}
$$$$
25
$$$$
26
$$$$
27
$$$$
28
$$$$
29
$$$$
30
$$$$
31
$$$$
32
$$$$
33
$$$$
34
$$$$
35
$$$$
36
$$$$
37
$$$$
38
$$$$
39
$$$$
40
$$$$
41
$$$$
42
$$$$
43
$$$$
44
$$$$
45
$$$$
46
$$$$
47
$$$$
48
$$$$
49
$$$$
50
$$$$
51
$$$$
52
$$$$
53
$$$$
54
$$$$
55
$$$$
56
$$

57

58

59

60 


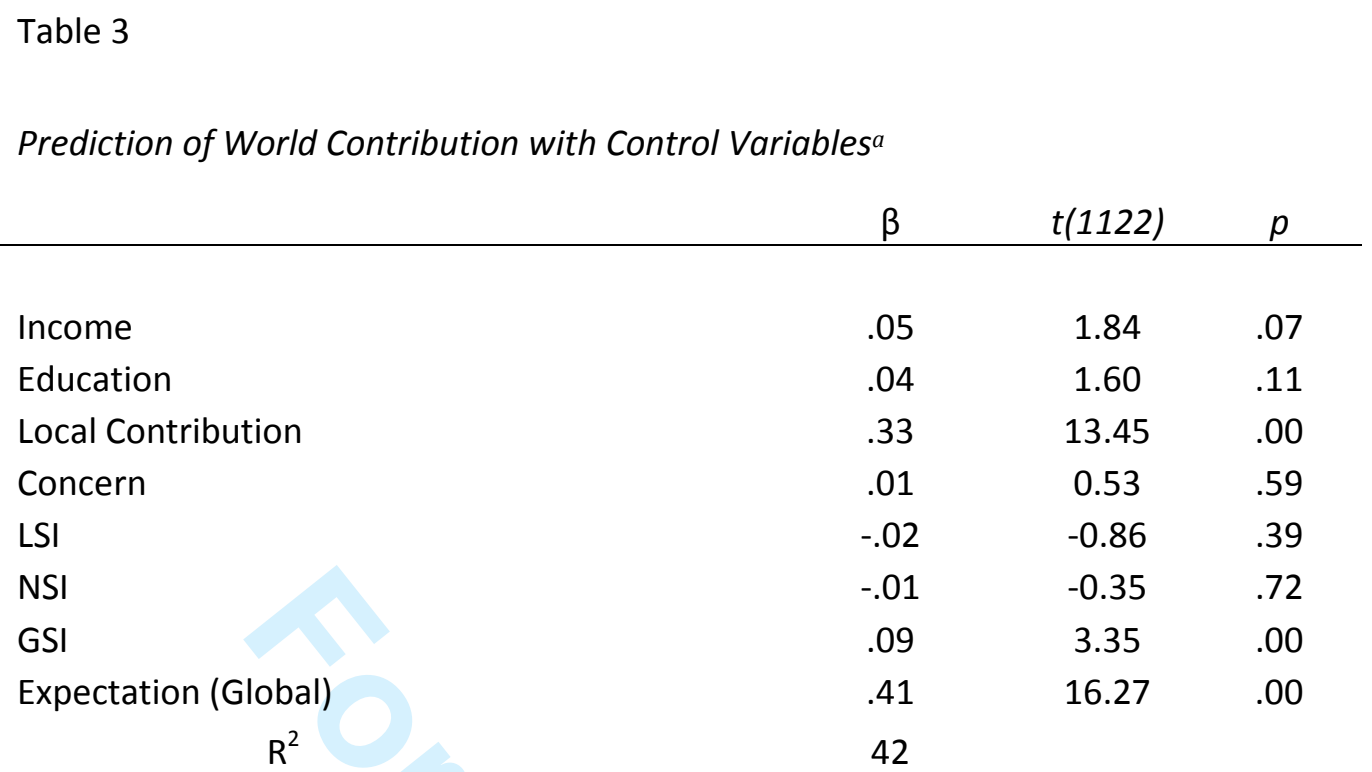

${ }^{\text {a }}$ Regression values after including country dummy codes as control variables 